\title{
Blowing snow in coastal Adélie Land, Antarctica: three atmospheric-moisture issues
}

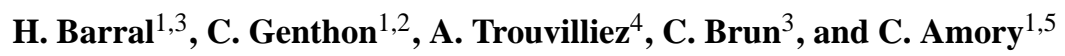 \\ ${ }^{1}$ CNRS, LGGE - UMR5183, 38000 Grenoble, France \\ ${ }^{2}$ Univ. Grenoble Alpes, LGGE - UMR5183, 38000 Grenoble, France \\ ${ }^{3}$ Univ. Grenoble Alpes, LEGI - UMR5519, 38000 Grenoble, France \\ ${ }^{4}$ Cerema, DTecEMF, LGCE, 29200 Brest, France \\ ${ }^{5}$ Univ. Grenoble Alpes Irstea, 38000 Grenoble, France \\ Correspondence to: C. Genthon (genthon@lgge.obs.ujf-grenoble.fr) and H. Barral (helene.barral@lgge.obs.ujf-grenoble.fr)
}

Received: 21 April 2014 - Published in The Cryosphere Discuss.: 2 June 2014

Revised: 25 August 2014 - Accepted: 15 September 2014 - Published: 22 October 2014

\begin{abstract}
A total of 3 years of blowing-snow observations and associated meteorology along a $7 \mathrm{~m}$ mast at site D17 in coastal Adélie Land are presented. The observations are used to address three atmospheric-moisture issues related to the occurrence of blowing snow, a feature which largely affects many regions of Antarctica: (1) blowing-snow sublimation raises the moisture content of the surface atmosphere close to saturation, and atmospheric models and meteorological analyses that do not carry blowing-snow parameterizations are affected by a systematic dry bias; (2) while snowpack modelling with a parameterization of surface-snow erosion by wind can reproduce the variability of snow accumulation and ablation, ignoring the high levels of atmospheric-moisture content associated with blowing snow results in overestimating surface sublimation, affecting the energy budget of the snowpack; (3) the well-known profile method of calculating turbulent moisture fluxes is not applicable when blowing snow occurs, because moisture gradients are weak due to blowing-snow sublimation, and the impact of measurement uncertainties are strongly amplified in the case of strong winds.
\end{abstract}

\section{Introduction}

In Antarctica, surface cooling and smooth sloping surfaces over hundreds of kilometres induce strong, frequent and persistent katabatic winds. More often than not, such winds transport snow and induce blizzards. Although some of the blizzards result from precipitating snow being transported by the wind, some of the blowing snow also originates from the erosion of previously deposited precipitation at the surface. In places, the contribution of eroding and blowing snow to the surface mass balance (SMB) of Antarctica is a major one, to the extent that no snow can accumulate even though snowfall occurs (Genthon et al., 2007). These are the windinduced "blue-ice" areas that affect $\sim 0.8 \%$ of the surface of Antarctica (Ligtenberg et al., 2014). Over the bulk of Antarctica, although estimates have been suggested from remote sensing (Das et al., 2013), only meteorological/climate models including parameterizations for blowing snow are likely to provide a fully consistent evaluation of the contribution of blowing-snow processes to the SMB of the ice sheet (Déry and Yau, 2002; Lenaerts et al., 2012b). Lenaerts et al. (2012a) computed that sublimation of blown particles removes almost $7 \%$ of the precipitation, considering the whole icesheet. Gallée et al. (2005) found about $30 \%$ along a $600 \mathrm{~km}$ transect in Wilkes Land. Yet, because the processes are complex and varied, such parameterizations and models must be carefully evaluated with in situ observations.

The fact that Adélie Land is one of the windiest and most blizzard-plagued regions in the world (Wendler et al., 1997) was already recognized back in the early days of Antarctic exploration (Mawson, 1915). This is because of the long fetch from the plateau, combined with topographic funnelling of the katabatic winds (Parish and Bromwich, 1991). Adélie Land is thus a favoured region for an observational characterization of blowing snow. Yet, access 
and logistics are difficult in Antarctica in general, and operations in Adélie Land are no exception. In addition, to observe blowing snow, one has to deploy and run measuring devices in the harsh weather conditions. One of the French permanent Antarctic stations (Dumont d'Urville station) is located on an island $5 \mathrm{~km}$ offshore from the coast of Adélie Land, allowing significant logistical support in the area. Thanks to this support, an SMB monitoring programme has been run since 2004. The GLACIOCLIM-SAMBA observatory (http://www-lgge.ujf-grenoble.fr/ServiceObs/ SiteWebAntarc/GLACIOCLIM-SAMBA.php) has collected annual SMB data stretching from the coast to more than $150 \mathrm{~km}$ inland, which, combined with historical data, have shown no significant SMB change over the last 40 years (Agosta et al., 2012). On the other hand, comparing the GLACIOCLIM-SAMBA observations with various models, including some that carry blowing-snow modelling, suggests that blowing snow does indeed contribute significantly to the SMB (Agosta et al., 2012).

To what extent do climate models that do not take into account blowing snow fail to reproduce the characteristics of the surface meteorology and climate of Antarctica? While blowing snow likely contributes to the SMB, it also impacts the near-surface atmosphere by further decreasing its negative buoyancy and reducing turbulence (Gallée et al., 2013). The negative buoyancy of the air is further increased because it is cooled by the evaporation/sublimation of the airborne snow particles. This is positive feedback for the katabatic flow. Besides transporting solid water, the near-surface atmosphere transports more water vapour than it would without blowing snow due to the sublimation of blown-snow particles. Some authors demonstrated through observations studies that snowdrift sublimation can exceed surface sublimation in coastal and windy Antarctic areas (Bintanja, 2001; Frezzotti et al., 2004). In fact, the issue of blowing snow is not limited to Antarctica, and historical studies first took place in mountainous regions. On the basis of direct in situ measurements, Schmidt (1982) calculated that sublimation amounts to $13.1 \%$ of the blowing-snow transport rate in Southern Wyoming during blizzard events. Schmidt also cites results by Tabler (1975) in the same area, estimating that $57 \%$ of the winter snowfall is evaporated during transport after remobilization from the surface. This is over flat surfaces exempt of katabatic wind. On the Antarctic slopes, air compression due to down-slope gravity flow induces adiabatic warming (Gosink, 1989): the air is warmer than it would be at rest or flowing over flat surfaces. As the air warms, it becomes more undersaturated. This is partially compensated by the sublimation of blowing snow. Thus, models that do not account for blowing snow are very likely to underestimate surface-air moisture in Antarctica.

Observations are needed to characterize not only the various aspects of the impacts of blowing snow on the SMB, but also surface meteorology and potential biases in models. Background surface-mass-balance information from

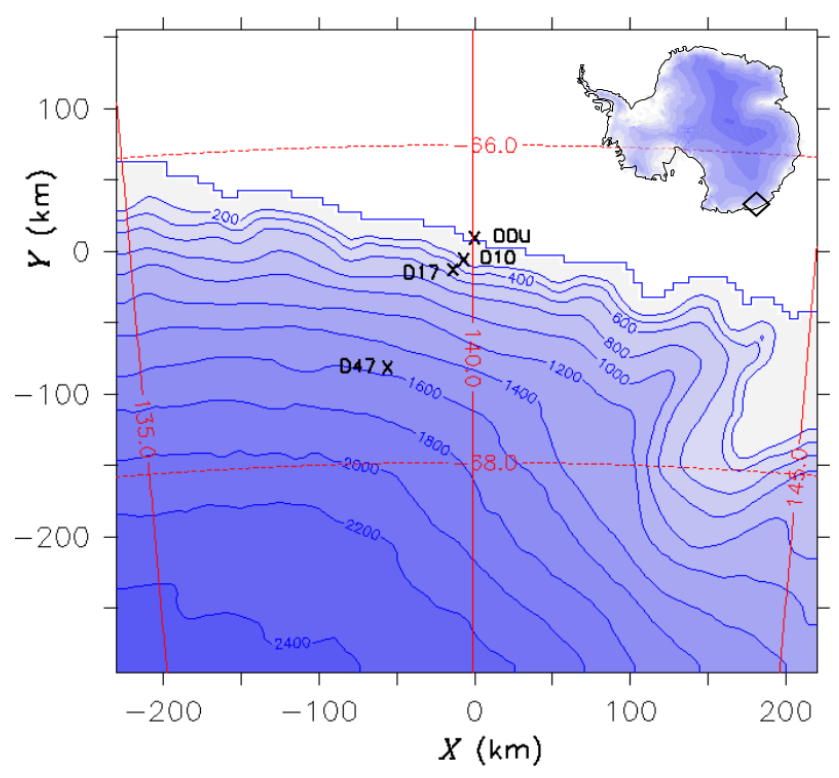

Figure 1. Topography of the area, with the location of the D17 site. Altitude lines are reported in metres.

GLACIOCLIM-SAMBA and good logistical support from the nearby Dumont d'Urville research station were major assets in initiating a multi-year blowing-snow monitoring campaign. Blowing snow and meteorological observation systems have been deployed and maintained since 2010. Instruments were deployed from the coast to $100 \mathrm{~km}$ inland (Trouvilliez et al., 2014). Here, we concentrate on the data obtained at site D17, about $10 \mathrm{~km}$ inland from the coast, because this is where the most extensive observation system was deployed. This is described in the data and model section (Sect. 2). An analysis of the data in terms of the relationship of atmospheric moisture with the occurrence of blowing snow is made in Sect. 3. The inability of various models without blowing snow, to reproduce the observed atmospheric moisture, is also demonstrated in this section. In Sect. 4, a snow-pack model with a parameterization of blowing snow is used to evaluate the importance and contribution of blowing snow at D17. In Sect. 5, latent heat fluxes are computed from profile observations and compared to the snow-pack model results. The uncertainties of the profile calculations are discussed. Section 6 provides the general conclusions.

\section{Data and model}

\subsection{Observation data}

Site D17 ( $66^{\circ} 43^{\prime} 26^{\prime \prime} \mathrm{S}, 139^{\circ} 42^{\prime} 21^{\prime \prime} \mathrm{E}$; $\sim 450 \mathrm{~m}$ a.s.l.) is located $\sim 10 \mathrm{~km}$ inland from the coast of Adélie Land (Fig. 1). Access is relatively easy in summer, but the site is not accessible in winter. Thus, the bulk of the instruments deployed at D17 must run in an automatic mode. A $7 \mathrm{~m}$ mast was 


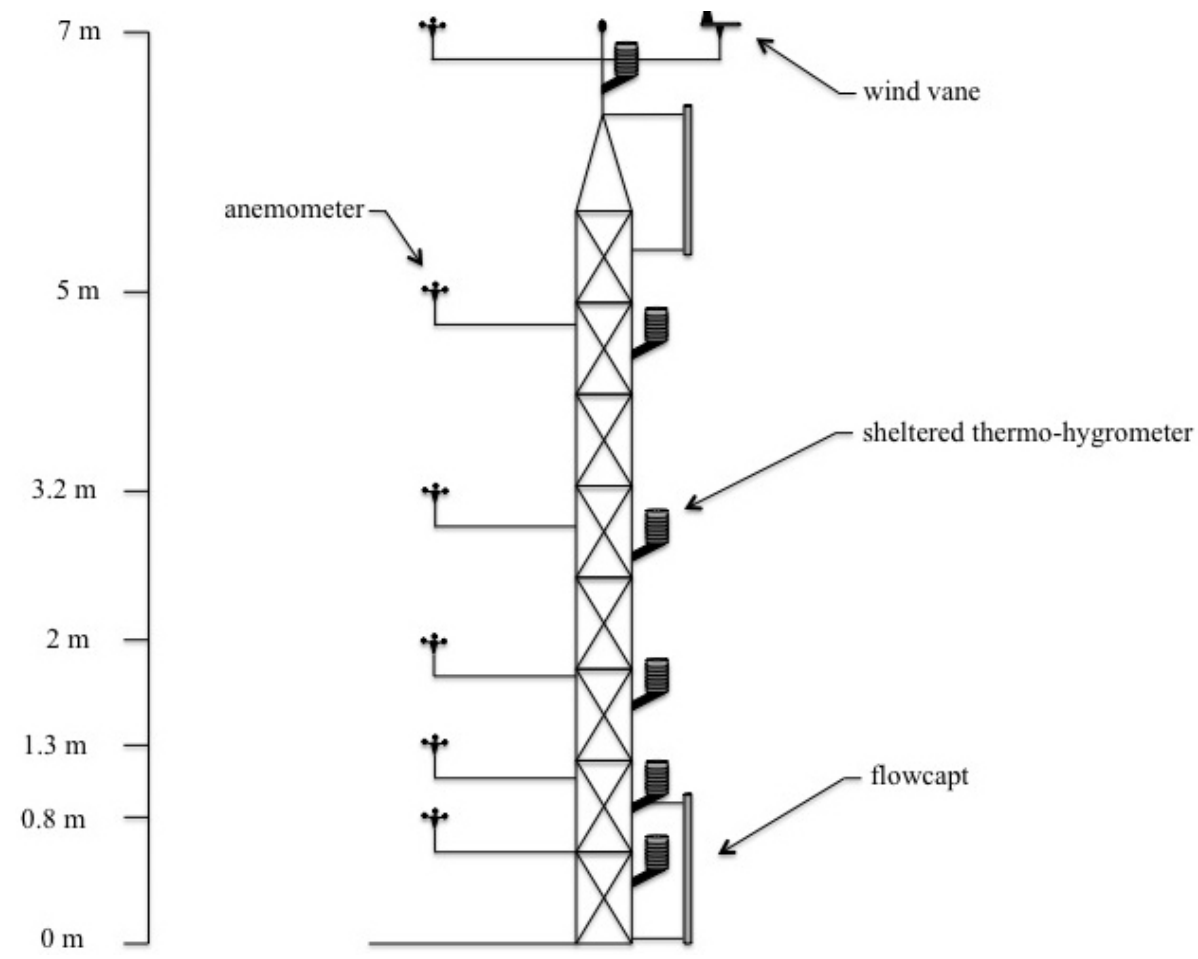

Figure 2. Schematic representation of the meteorological profiling and blowing-snow measurements at D17.

erected early in 2010 (Fig. 2). Profiles of wind, temperature and moisture are recorded along the mast. Temperature and moisture are measured using Vaisala HMP45 sensors in MET21 radiation shields. Because winds are remarkably persistent at D17, wind ventilation of the radiation shields that house the thermometers prevents warm biases, as reported by Genthon et al. (2011) on the Antarctic plateau. Texas Instrument NRG40C cup anemometers were initially used to sample wind. They proved to be insufficiently robust for the extreme Adélie Land environment and were later replaced with Vector A100 cup anemometers. Information on blowing snow was obtained using IAV Technologies FlowCapt sensors ${ }^{1}$. Although FlowCapts are very good at detecting blowing snow, the original design resulted in significant errors in estimating the blowing-snow fluxes (Cierco et al., 2007). The sensors at D17 are of a more recent design, which significantly improves, although not necessarily solves, problems with estimating blowing-snow fluxes (Trouvilliez, 2013).

Data are sampled with a $10 \mathrm{~s}$ time step, and the $30 \mathrm{~min}$ statistics are stored by a Campbell CR3000 data logger. The $30 \mathrm{~min}$ averaged data are used in the present work. All instruments were set up within manufacturer-stated operating range of temperature and wind at D17. The HMP45 are factory calibrated to report relative humidity with respect to liquid water rather than to ice, even below $0^{\circ} \mathrm{C}$. Goff and Gratch (1945) formulae are used to convert to relative

\footnotetext{
${ }^{1}$ http://www.flowcapt.com/
}

humidity $(\mathrm{RH})$ with respect to ice $\left(\mathrm{RH}_{\mathrm{wri}}\right)$, using the sensor temperature reports in the conversion. Conversions occasionally yield values above $100 \%$. These values are attributed to instruments and Goff-Gratch conversion accuracy limitations. Indeed, while supersaturations have been reported in Antarctica (Anderson, 1996; Genthon et al., 2013), they only occur in very cold clean atmosphere devoid of cloud condensation nuclei. They cannot be sustained at D17 because of relatively high temperatures. Moreover, while snow is blowing, snow crystal particles provide a large number of cloud condensation nuclei. Therefore, the result of the conversion is capped to $100 \%$. Some of the observations, after such postprocessing, are shown in Fig. 3.

The elevation of the instruments above the surface has changed with time due to snow accumulation and ablation. The profile initially ranged from 87 to $696 \mathrm{~cm}$. The instruments were raised back to original height each summer, when access was possible. No information on local temporal variations is available before 2013 or the deployment of a Campbell SR50A acoustic depth gauge (ADG). A small stakes network (nine stakes over $\sim 200 \mathrm{~m}$ ) was deployed in early 2011, but this is surveyed in summer only. A basic automatic weather station (AWS, single level temperature, moisture and wind) equipped with an ADG runs about $500 \mathrm{~m}$ away. The AWS location is too remote from the mast for the snowheight data to be confidently used to correct changes in the elevation of the mast instruments above the surface. Indeed, the GLACIOCLIM-SAMBA observations reveal very strong 

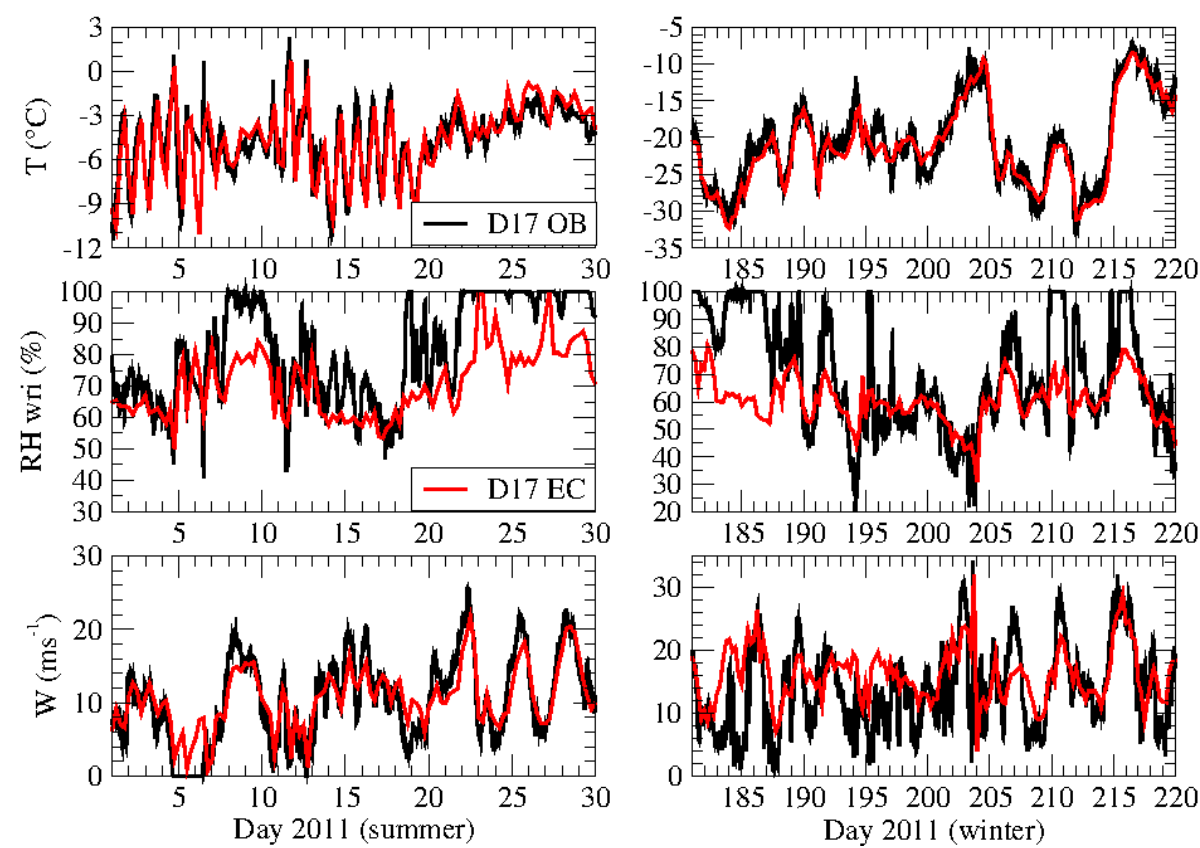

Figure 3. D17 meteorology, $2 \mathrm{~m}$ temperature $(T)$ and relative humidity with respect to ice $\left(\mathrm{RH}_{\mathrm{wri}}\right)$, and $10 \mathrm{~m}$ wind, through two 30 day samples in 2011, in austral summer (left panels) and winter (right panels). Observations (D17 OB) are in black, ECMWF operational analyses (D17 EC) in red. See text for approximation and extrapolation to 2 and $10 \mathrm{~m}$ for the observations.

variability of accumulation at sub-kilometre scale in the area (Agosta et al., 2012), clearly related to the distribution of blowing snow by the wind. Nevertheless, we used this data to compare results from a snow pack model in terms of variability (Sect. 4); we checked that the way the data are used here is not strongly affected by sub-annual changes of the elevation of the instruments above the surface. Such changes are thus neglected and the initial, annually readjusted instrument heights are used.

Data at standard levels ( $2 \mathrm{~m}$ for temperature and moisture, $10 \mathrm{~m}$ for wind) are necessary to compare with other sources of meteorological information (Sect. 2.2) and to force a snow model (Sect. 2.3). Reports from the third mast level $(256 \mathrm{~cm})$ are used as proxy for $2 \mathrm{~m}$ meteorology. Because of instrumental uncertainties, and the fact that wind and turbulent mixing are often strong, this is considered an acceptable approximation of $2 \mathrm{~m}$ for our purpose. The $10 \mathrm{~m}$ wind is extrapolated using log-profile approximation:

$V_{10}=V_{h} \frac{\ln \left(10 / z_{0}\right)}{\ln \left(h / z_{0}\right)}$

where $V_{h}$ is wind speed $h$ metres above surface $(10 \mathrm{~m}$ for standard level, mast level for observation) and $z_{0}$ is the surface roughness. This is an acceptable approximation for our purpose, since the boundary layer is under near-neutral condition most of the time (Sect. 5). Using $z_{0}=0.25 \mathrm{~cm}$, the $10 \mathrm{~m}$ wind would be very similar if extrapolated from the fourth or higher mast levels. Further discussion of this estimation for $z_{0}$ is provided in Sect. 4. Here, the fifth level
(4.8 $\mathrm{m}$ ) wind, rather than the top one $(\sim 7 \mathrm{~m})$, is extrapolated because of significant gaps in the record from the latter.

\subsection{Meteorological-analysis data}

The ECMWF (European Center for Medium-Range Weather Forecasts) operational meteorological analyses (ECMWF, 1989) ${ }^{2}$ compare well with the observation for temperature and reasonably for wind (Fig. 3). The meteorological analyses are the results of the assimilation of in situ and satellite observations into a meteorological model. The daily radiosounding at Dumont d'Urville station, and reports from 2 Antarctic Meteorological Research Center (AMRC) $\mathrm{AWSs}^{3}$ within less than $100 \mathrm{~km}$ of D17, are both transmitted to the global telecommunication system and thus, in principle, available in time for operational analysis at ECMWF. This probably contributes to the good agreement with observation. On the other hand, atmospheric moisture is underestimated, suggesting that it is not properly assimilated. Persistent large discrepancies between the model and the observations may result in the rejection of the latter in the analysis process.

The operational analyses are used here, rather than reanalyses, because horizontal resolution is higher $(\sim 70 \mathrm{~km}$ for ERA-interim versus $\sim 16 \mathrm{~km}$ for operational analysis since 2010). Near the coast, resolution is an important issue with respect to contamination by the ocean surface: grid points

\footnotetext{
${ }^{2}$ http://data-portal.ecmwf.int/

${ }^{3}$ http://amrc.ssec.wisc.edu/
} 
that "see" the ocean, particularly when it is free of sea ice, are likely affected by larger heat and moisture exchange than grid points located inland. Also, the katabatic winds do not persist over the ocean and may thus be underestimated. The meteorological analyses from the grid point nearest to D17 on the model's T512 reduced Gauss grid, the surface of which is $100 \%$ continental ice (no ocean), are used here. The grid point is centered within less than $20 \mathrm{~km}$ of the real D17, model surface elevation being $540 \mathrm{~m}$, close to that of D17. The ECMWF analyses are used in Sect. 4 as surface atmospheric boundary conditions for a snow-pack model described in Sect. 2.2. The snow-pack model needs input of near-surface temperature, moisture and wind, but also precipitation, radiation and cloudiness. For the first group, observational data are used alternatively with meteorological analyses. For the second group, only meteorological analyses are used (comprehensive observational data sets are not available). It may be important to note that cloudiness is really analysed, whereas precipitation and radiation are not; they are, in fact, forecast by the ECMWF model initialized by the analyses.

\subsection{Snow-pack model}

The Crocus snow-pack model (Brun et al., 1989, 1992) was initially developed to simulate Alpine seasonal snow and assist in avalanche-risk evaluation. Crocus has also been used in various studies outside the originally planned domain of application, including studies of polar snow over ice sheets (Dang et al., 1997; Genthon et al., 2001, 2007). Crocus is a horizontally one-dimensional, vertically multilayered physical model of the snow cover. It explicitly calculates the surface-snow height, mass and energy budgets at hourly steps, including turbulent heat and moisture surface exchanges with the atmosphere and outgoing radiation, and the internal balance of mass and energy. There are up to 50 subsurface layers through which mass and energy are exchanged to account for physical processes, such as heat diffusion, radiation transfer or liquid-water percolation. Phase changes are taken into account and snow densification and metamorphism are parameterized, affecting mass and energy transfer and changing surface albedo.

\section{Atmospheric moisture in relation to blowing snow, observations and models}

An analysis of the data in terms of the relationship between atmospheric moisture and occurrence of blowing snow is made in the present section.

\subsection{Relationship between atmospheric moisture and occurrence of blowing snow in the observations}

Figure 4 shows the 2011-2012 records of observed relative humidity with respect to ice $\left(\mathrm{RH}_{\mathrm{wri}}\right)$ at the lower $(0.87 \mathrm{~m})$

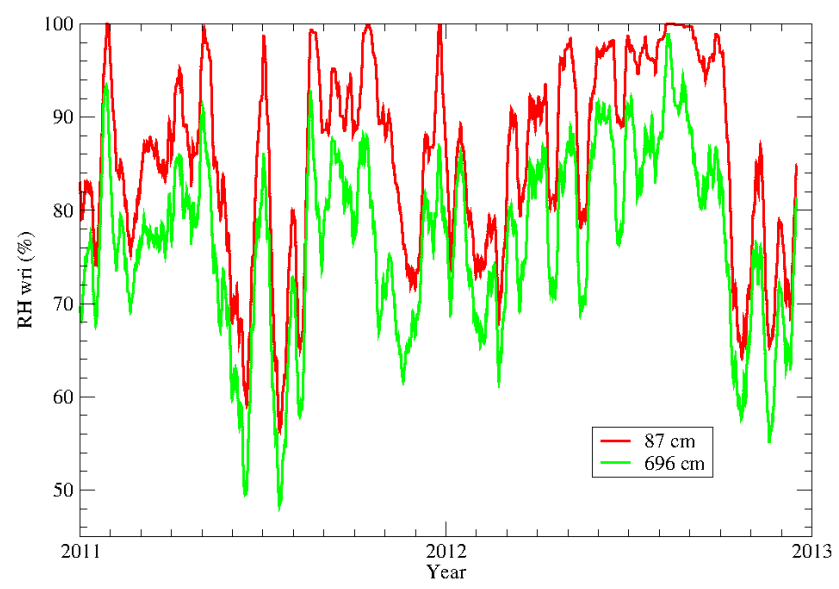

Figure 4. Relative humidity with respect to ice $\left(\mathrm{RH}_{\mathrm{wri}}\right)$ at the lower $(87 \mathrm{~cm})$ and upper $(696 \mathrm{~cm})$ measurement levels. A 10-day running average is used to filter out the faster (diurnal, synoptic) components of variability.

and upper $(6.96 \mathrm{~m})$ levels on the mast. A 10-day running average is used to smooth out the shorter-term variability, including diurnal and fast synoptic variability. For the entire duration of the 2-year observations, relative humidity is very high in the range about $\mathrm{RH}_{\mathrm{wri}} \sim 70 \%$, and $10 \%$ larger when measurements are performed close to the ground surface. A zoom on a summer episode and a winter episode is shown on Fig. 3. Very low $\mathrm{RH}$ values below $\mathrm{RH}_{\mathrm{wri}}=30 \%$ do occur, which one would expect to be related to katabatic winds that are to be relatively dry in terms of $\mathrm{RH}$, due to adiabatic warming as pressure increases downslope. Observations show that $\mathrm{RH}$ values close to or at saturation occur frequently as well, which is not a direct effect of the katabatic process. We presently analyse the effect of blowing snow on such an increase of relative humidity. The FlowCapt instruments on the D17 mast allow to sort data according to occurrence of blowing snow. One of the instruments failed and data from this instrument were unavailable over a major portion of the observation campaign. Thus, only one of the two instruments - the one near the surface - is used to evaluate blowing snow.

Atmospheric moistening by sublimation of blown snow is expected to depend on blown-snow quantities. A large blowing-snow flux threshold at $300 \mathrm{~g} \mathrm{~m}^{-2} \mathrm{~s}^{-1}$ is used here to highlight the saturation effect, but this threshold is only passed $2 \%$ of the time.

Figure 5 shows the mean vertical profiles of $\mathrm{RH}_{\mathrm{wri}}$ when large amounts of blowing snow are detected (flux $>300 \mathrm{~g} \mathrm{~m}^{-2} \mathrm{~s}^{-1}$ ), respectively weaker amounts (flux $<300 \mathrm{~g} \mathrm{~m}^{-2} \mathrm{~s}^{-1}$ ). Large blowing-snow quantities and high relative humidity are clearly related, with a mean moisture content very close to saturation. $\mathrm{RH}_{\mathrm{wri}}$ is strongly reduced when blowing snow is weaker and decreases more significantly with height, as well. This process is consistent 


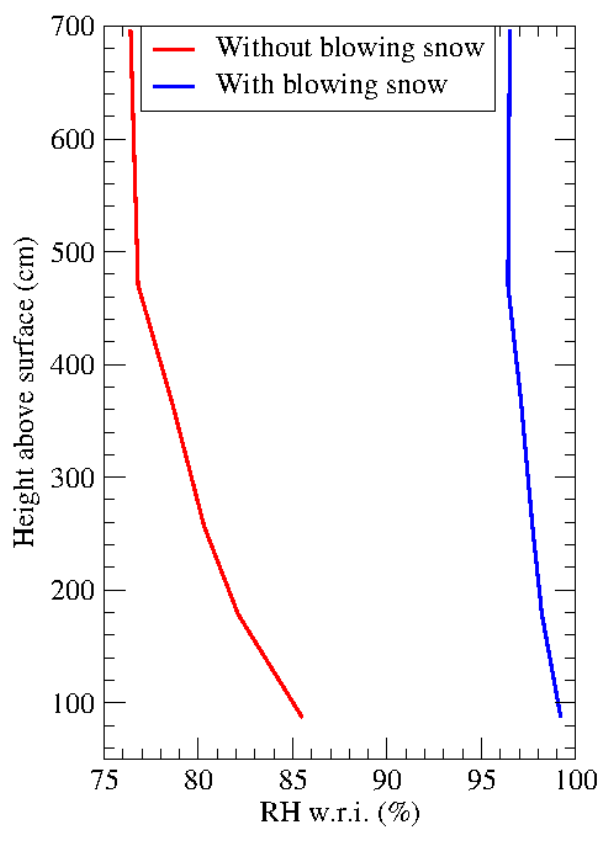

Figure 5. Profiles of mean 2011-2012 observed relative humidity with respect to ice, when blowing snow occurs to large (blue) and weak or null (red) quantities.

with a major source of moisture by surface sublimation when there is no blowing snow. Moistening by the sublimation of the wind-blown snow particles results in a vertical profile to be much more homogeneous. A residual gradient may be due to either a contribution of surface sublimation, or vertical gradients of blowing snow and thus of blown-snow sublimation.

The present results are consistent with observations at the AMRC AWS at site D10, $7 \mathrm{~km}$ downslope from D17, where $\mathrm{RH}_{\text {wri }}$ is above $90 \%$ more than $40 \%$ of the time. At $\mathrm{D} 47, \sim 100 \mathrm{~km}$ upslope and reputedly one of the windiest places in Adélie Land (Wendler et al., 1993), it is above $90 \%$ more than $77 \%$ of the time. At Halley on the Brunt Ice Shelf in West Antarctica, $\mathrm{RH}_{\text {wri }}$ is reported to increase with wind speed, as well (Mann et al., 2000). This is interpreted as the signature of the sublimation of blowing snow when the wind is strong enough to lift snow from the surface. In their study, relative humidity is shown to decrease along the vertical profile above the surface (between $z=1.5 \mathrm{~m}$ and $z=11 \mathrm{~m}$ ), and the vertical gradient reduces when the wind is stronger, consistently with observations at D17 (Fig. 5). The present results are qualitatively consistent, as well, with observations performed in southern Wyoming (continental USA) during a nocturnal blizzard $70 \mathrm{~cm}$ above the snow surface (Schmidt, 1982). They report events of blowing-snow flux from 90 to $400 \mathrm{~g} \mathrm{~m}^{-2} \mathrm{~s}^{-1}$ and $\mathrm{RH}_{\mathrm{wri}}$ ranging from 80 to $88 \%$, and they consider these as relatively high values of relative humidity that attribute to sublimation of blowing snow. Differences in saturation level with the present study may be related to a shorter wind fetch and thus a weaker development of the blowing-snow layer.

\subsection{Relationship between atmospheric moisture and occurrence of blowing snow in atmospheric model}

The atmospheric model used to produce ECMWF analyses ignores blowing snow and its moistening effect. This is likely the reason why relative humidity is underestimated and frequent saturation is not reproduced. Most meteorological and climate models ignore blowing snow, and are thus likely to similarly underestimate atmospheric moisture on the Antarctic slopes. Comparing simulations with a same meteorological model running with and without a parameterization for blowing snow, including blown-snow sublimation, Lenaerts et al. (2012a) report a significant increase of $\mathrm{RH}_{\text {wri }}$ at the coast of Queen Maud Land in better agreement with the observations in the latter run. The occurrence of blowing snow and the blown-snow quantity depend on various snow and atmosphere parameters (Gallée et al., 2013), obviously including wind speed. For models that do not parameterize blowing snow, the most straightforward proxy for blowing-snow occurrence is probably wind speed. Figure 6 shows the distributions of $\mathrm{RH}_{\mathrm{wri}}$ values for wind speed above or below $12 \mathrm{~m} \mathrm{~s}^{-1}$, an arbitrary blowing-snow proxy threshold, and for all values of wind. The distribution is plotted for the observations and the ECMWF analyses at D17, and for two climate models in the CMIP5 (Climate Model Intercomparison Project $5^{4}$ ) archive. Their continental grid point closest to D17 is used.

The data are sorted in $10 \%$ wide RH bins, from $0-10$ to $100-110 \%$, frequencies in the latter bin obviously being 0. A strong maximum of the distribution in the 90 $100 \% \mathrm{RH}_{\mathrm{wri}}$ bin shows that conditions close to saturation occur frequently in the observations. The distribution shows lower frequency in the range $70-80 \%$ for weaker winds, with still significant contributions in the $90-100 \%$ bin. All models and analyses are consistently dryer than the observations. None of the models or analyses reproduce a distribution with large counts in the high RH bins, as observed. ECMWF and CanAM4 tend to produce slightly higher, rather than lower, values of RH when the wind is weaker, possibly a signature of the relative dryness of the stronger katabatic winds. MRI-GCM3 is consistently too dry. Thus, all models lack a source of atmospheric moistening, and they fail to show a definite increase of atmospheric moisture with wind speed, as observed. Among the possible interpretation is the fact that none of the models account for occurrence and evaporation of blowing snow.

\footnotetext{
${ }^{4}$ http://cmip-pcmdi.llnl.gov/cmip5/
} 

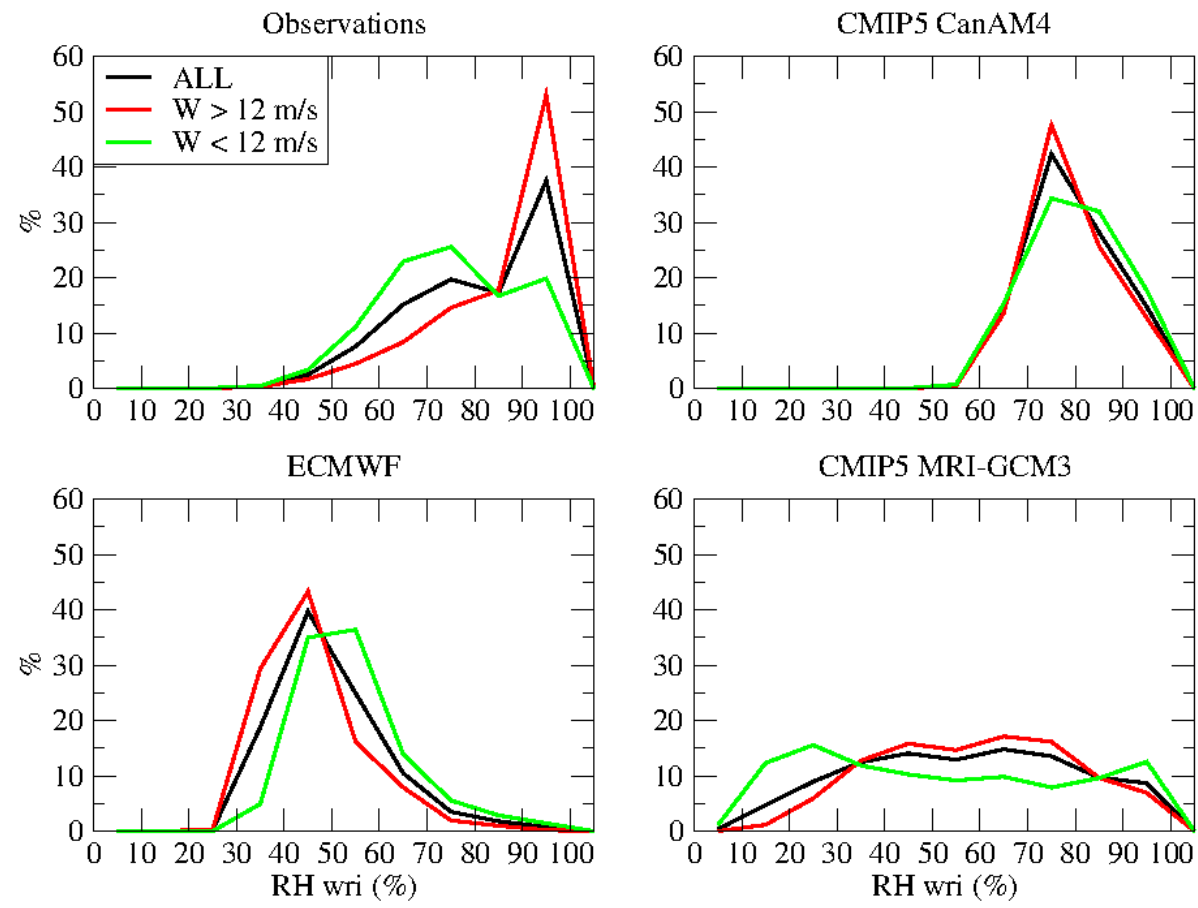

Figure 6. Frequency distribution of RH wri values, for $10 \mathrm{~m}$ wind speed above (red) or below (green) $12 \mathrm{~m} \mathrm{~s}^{-1}$, or all cases (black), in the D17observations, the ECMWF operational analyses, and simulations by two general circulation models from the CMIP5 archive, CanAM4 and MRI-GCM3. The simulations are of the AMIP (Atmospheric Model Intercomparison Project) type; that is, the atmospheric component of the climate models is used with prescribed observed monthly sea-surface boundary conditions, but turbulent fluxes on continental surfaces are simulated. Results are shown for two models in the archive for which the 3-hourly AMIP results for both surface wind and for $\mathrm{RH}_{\mathrm{wri}}$ are available.

\subsection{Relationship between atmospheric moisture and wind speed}

Even the dry values in the ECMWF analyses may be surprising considering that, although the moisture holding capacity of the katabatic air increases through adiabatic compression, the flow is a very turbulent one over an infinite source of potential sublimation at the surface. A number of AMRC AWSs report atmospheric moisture. AWSs D10, Gill and Bonaparte Point do. D10 is only $\sim 7 \mathrm{~km}$ from D17, in a very similar environment, although closer to the coast and the ocean. This is a proxy for D17 in the following intercomparison of data from AMRC AWSs. Station Gill $\left(178.59^{\circ} \mathrm{W}, 79.93^{\circ} \mathrm{S}\right)$ is located on the Ross Ice Shelf. The mean temperature is lower by about $10^{\circ} \mathrm{C}$, and the mean wind is about one-third of that at D10. Bonaparte Point $\left(64.07^{\circ} \mathrm{W}, 64.78^{\circ} \mathrm{S}\right)$ is the only AMRC AWS at a latitude close to that of D17, besides D10. It is located on an island on the western side of the Antarctic Peninsula. Temperature is about $10^{\circ} \mathrm{C}$ higher, and the mean wind speed is about half that of D10. The three stations are near sea level. Only D10 is exposed to strong katabatic flow. Figure 7 shows the distributions of $\mathrm{RH}_{\mathrm{wri}}$ for wind speed above or below $8 \mathrm{~m} \mathrm{~s}^{-1}$. The threshold wind is less than for Fig. 6 because the height of the wind sensor on the AMRC AWSs, although not well known due to snow accumulation between visits, is always significantly less than $10 \mathrm{~m}$. A lower wind threshold is thus a very approximate correction for a lower sensor height.

The counteracting effects of the katabatic wind comes out for D10, similarly to D17 (Fig. 6), with a clear bimodal distribution of $\mathrm{RH}_{\mathrm{wri}}$. At Gill, moisture is much more consistently high, with virtually no sensitivity to wind speed. This indicates that blowing snow, if any, does not affect air moisture, which is close to saturation anyway because of surface sublimation and no katabatic drying. Sensitivity to wind speed is also very low at Bonaparte Point, and a broad distribution suggests that moisture is added to the air by a combination of surface sublimation and synoptic advection. The observations in Adélie Land (D10) are the only ones consistent with a major impact of blowing snow: values are high when the wind is strong and blowing snow occurs; they are lower with weaker winds, when less or no blowing snow occurs and the katabatic drying effect takes over.

\section{Snow-pack modelling}

In this section, the snow-pack model Crocus (Sect. 2.3) is used with a parameterization of surface-snow erosion. Crocus requires $2 \mathrm{~m}$ atmospheric temperature and relative 

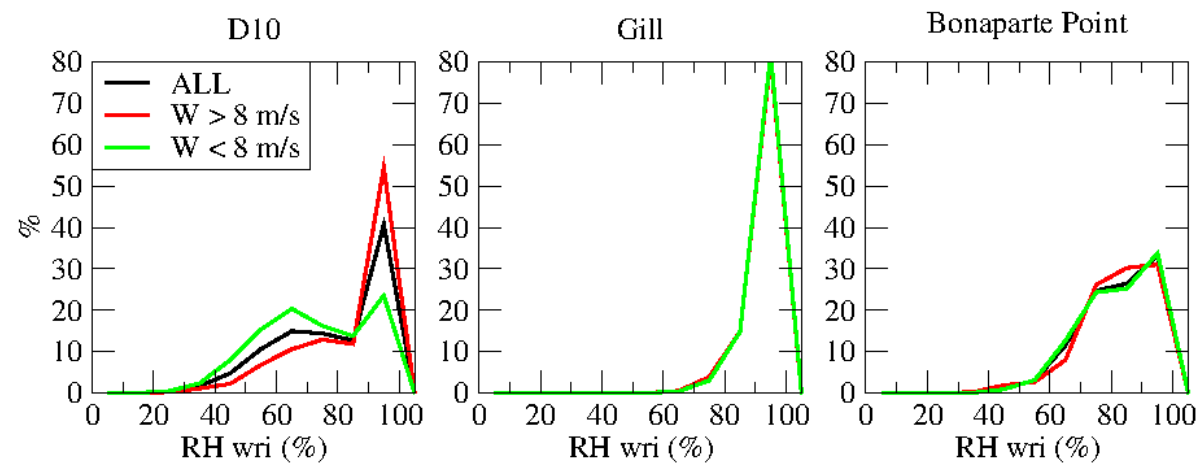

Figure 7. Same as Fig. 6 for three AMRC automatic weather stations. A lower wind threshold $\left(8 \mathrm{~m} \mathrm{~s}^{-1}\right)$ is used because the measurement height is less than $10 \mathrm{~m}$.

humidity, $10 \mathrm{~m}$ wind speed, precipitation quantity and phase, downwelling solar and thermal radiation, and cloud cover. This is all available from the ECMWF analyses and shortterm forecasts, as described in Sect. 2.2, but only partially from the observations. First, for some parameters of the model, the surface-snow-erosion parameterization and input of atmospheric fields have been adapted to Antarctic snow and conditions. Then, Crocus is alternately run with full input meteorology from ECMWF analyses, as in Genthon et al. (2007), or from a combination of the D17 mast observations and, where and when missing or not available, the ECMWF analyses. The input meteorology is interpolated to the required hourly time step from the $6 \mathrm{~h}$ analyses, or sampled from the $30 \mathrm{~min}$ observations.

\subsection{Method: model adaptation for Antarctic snow and blowing-snow parameterization}

Various aspects of the Antarctic snow-pack significantly differ from those of Alpine snow. Previous works (Genthon et al., 2007 for a comprehensive description) adapted the parameterizations for the roughness and albedo of surface snow, and snow density at deposition. A parameterization for snow erosion by wind was developed and implemented by Genthon et al. (2007) to simulate accumulation and ablation on a stretch of blue ice at the coast of Adélie Land. Yet, because Crocus is a one-dimensional model, it cannot explicitly handle the horizontal transport and exchange of blown snow. Over the blue ice, due to the proximity of the ocean, blown snow was assumed to be fully exported. At D17, a large net contribution from snow blown upstream is parameterized. Along with other atmospheric surface parameters, air moisture is prescribed. Thus, the model has no explicit (and no need for) parameterization for the sublimation of airborne snow. Observations reported in Sect. 3 show that blowing-snow sublimation increases atmospheric moisture, often to saturation level. The feedback on surface sublimation is taken into account in the model when the observed meteorology is used as input.
Here, the same parameters as in Genthon et al. (2007) over blue ice are used, except for the following:

- Consistently with the evaluation of the $10 \mathrm{~m}$ wind from mast observation (Sect. 2.1), a roughness length $z_{0}=0.25 \mathrm{~cm}$ is used in the calculations of the friction velocity $u_{*}$ for bulk heat and moisture-turbulent exchange at the surface and for the parameterization of snow erosion. This is significantly larger than over blue ice $(0.016 \mathrm{~cm})$ in Genthon et al. (2007), because snow dunes and sastrugi increase roughness, and also possibly because of more significant topography (glacier through) upstream. Although $z_{0}$ has been suggested to increase with friction velocity (Bintanja and van den Broeke, 1995), this results was challenged (Andreas, 2011). The value of $z_{0}$ is kept constant here.

- The short-term forecasts of precipitation are amplified by a factor of 1.2. No such multiplication factor was found necessary over blue ice. A precipitationformation (condensation) increase of such amplitude, from the coast to D17 upslope only $\sim 10 \mathrm{~km}$ in distance and $\sim 400 \mathrm{~m}$ in elevation, is not likely. In Genthon et al. (2007), observations of the accumulation and ablation on blue ice were taken from a stake network, which was surveyed less than 10 times a year and only two to four times in winter. Here, an ADG provides a continuous high-resolution record of accumulation/ablation, which, despite limited spatial significance, yields an accurate local estimate of snow-height increase during events having time scales of snowfall. The multiplication factor is necessary to, on average, account for the observed amplitude of those events (Fig. 8). There are no in situ observations of precipitation to directly evaluate ECMWF in Antarctica. Palerme et al. (2014) report good agreement between ECMWF ERA-I reanalyses and annual mean snowfall estimated from satellites, but not with the spatial resolution required for an assessment at the scales considered here. 


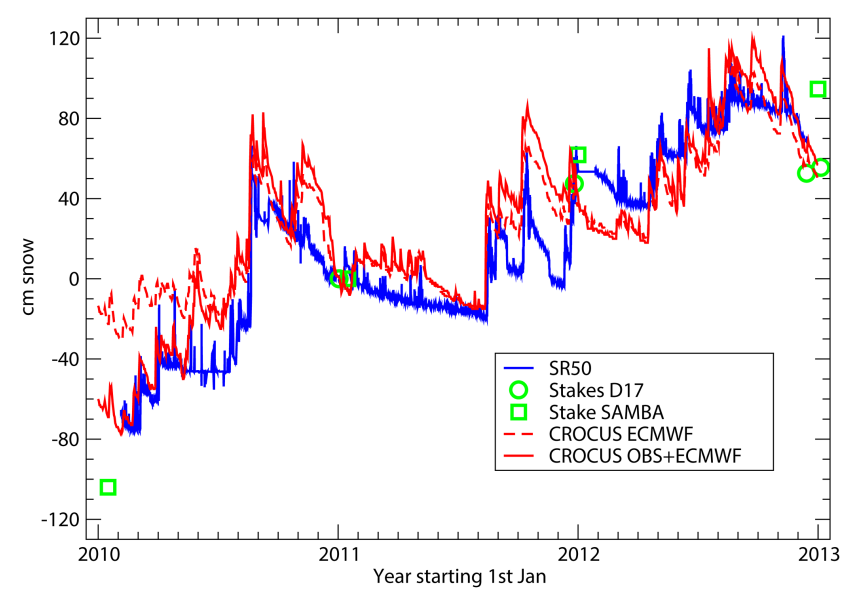

Figure 8. Observed (ADG in blue, GLACIOCLIM-SAMBA and D17 stakes in green) and simulated (Crocus model with ECMWF meteorology in red dashed line, with combined ECMWF and observed meteorology in red solid line) snow-pack height evolution over 2010-2012.

Agosta et al. (2012) show a 5 to $25 \%$ underestimation of precipitation minus surface sublimation in ERAI reanalyses compared to the GLACIOCLIM-SAMBAstake observations of SMB averaged at the spatial resolution of the analyses. On the other hand, the spatial variability within a model grid box, at a kilometre scale, can be large. Over the 10 GLACIOCLIMSAMBA stakes within $5 \mathrm{~km}$ of D17, the relative SMB variance is $\sim 30 \%$. The strong katabatic winds transport and redistribute snow and can locally concentrate deposition, whether this is snow eroded from the surface or fresh snowfall. A significant yet local multiplication factor for snowfall is thus not inappropriate; the factor 1.2 is used to amplify the ECMWF short-term forecasts of precipitation.

- On blue ice, the eroded snow was fully lost by the surface, either by sublimation or by export to the ocean right next to the blue-ice field. At D17, $11 \%$ of the parameterized erosion only results in a net local loss, as some of the snow originating upstream feeds the local snow pack. This is an adjusted parameter in the model to produce rates of snow-pack reduction during ablation periods, which, on average, agree with observations (Fig. 8). A long snow-pack reduction period in the first part of 2011 is overestimated though. On the other hand, shorter periods, e.g. at the end of 2011 and beginning of 2012, agree well. Again, one has to keep in mind that the ADG data are very local observations, and may not have sufficient spatial significance to expect a consistent agreement. Also, uncertainties with the other components of the snow-pack balance contribute to some disagreement.

\subsection{Results}

Crocus is alternately run with full input meteorology from ECMWF analyses or from a combination of the D17 mast observations and the ECMWF analyses. Figure 8 displays the observations and simulations of snow-pack-height variations at D17. The reference snow pack is that of 1 January 2011, about when the D17 nine-stakes network was deployed (green circles). Observation and model series are adjusted to this reference on the $y$ axis. The GLACIOCLIMSAMBA data confirm that the mean annual accumulation is positive at D17 (Agosta et al., 2012). The green squares in Fig. 8 show the measured snow accumulation at the GLACIOCLIM-SAMBA stake near D17 having the mean accumulation closest to that reported by the ADG (blue curve). This allows one to extend stake information 1 year back in time, from the nine-stake network at D17, showing significantly more accumulation in 2010 than in 2011 or 2012. In fact, the mean 2010 accumulation along the GLACIOCLIM-SAMBA stakes system was the highest on record.

The ADG also reports larger accumulation in 2010 than in 2011 and 2012, although it is not quite the increase the stake suggests. Both pieces of information have very limited spatial significance, though, and thus cannot be expected to fully compare due to small-scale spatial noise in accumulation (Genthon et al., 2005). A Crocus simulation using meteorological boundary conditions purely from the ECMWF analyses and short-term forecasts (red dashed curve) misses the stronger accumulation in 2010. On the other hand, a simulation using the observed meteorology, as available (Sect. 2.1), complemented with ECMWF data when missing in the observation (Sect. 4.1) reproduces the 2011-2012 mean accumulation and yields more accumulation in 2010 than in 2011 and 2012. Using the observed meteorology, rather than the analysed meteorology, thus makes a difference. Sensitivity tests (not shown) swapping observed and ECMWF components of meteorology show that differences in the wind, on the one hand, and of the temperature and relative humidity (together), on the other hand, equally contribute (by about $50 \%$ each) to the differences in the model results.

One expects surface sublimation to differ when atmospheric-moisture saturation differs. In particular, no sublimation can occur if the atmosphere is saturated. In fact, in that case, in a katabatic flow, inverse sublimation (direct solid condensation of atmospheric moisture) may even be expected. Indeed, because the near-surface air is warmer than the snow surface due to compression, the near-surface relative humidity is greater than that of the overlying air. The mean simulated surface latent heat flux, and conversion in water equivalent, are given in Table 1 for four simulations that combine observed and analysed meteorology differently. Differences between observed wind (S2) and analysed wind (S3) have a small impact on sublimation. Thus, the high sensitivity of the snow pack 
model to small differences in wind (Fig. 3) are due to the high sensitivity of blowing-snow erosion to wind. On the other hand, and not unexpectedly, differences in atmospheric moisture make up for most of the difference in surface sublimation. Using observed moisture rather than analyzed moisture, cuts sublimation by almost $50 \%$.

\section{Bulk and profile moisture flux calculations}

In this section, the moisture-turbulent fluxes calculated by the snow-pack model are compared to fluxes calculated with the profile method. Then, the impact of measurement uncertainties on flux calculations is discussed.

\subsection{Method}

Turbulent surface fluxes are computed in the Crocus model (Table 1) using a bulk formulation (Martin and Lejeune, 1998):

$$
\begin{aligned}
& \mathrm{SHF}=\rho c_{p} C u_{\mathrm{a}}\left(T_{\mathrm{a}}-T_{\mathrm{s}}\right) \\
& \mathrm{LHF}=\rho L_{\mathrm{s}} \frac{M_{\mathrm{v}}}{M_{\mathrm{a}}} C u_{\mathrm{a}}\left(q_{\mathrm{a}}-q_{\mathrm{s}}\right) .
\end{aligned}
$$

$\rho$ is the air density, $c_{p}$ the specific heat of air, $L_{\mathrm{S}}$ the ice latent heat of sublimation, $\frac{M_{\mathrm{v}}}{M_{\mathrm{a}}}$ is the ration of water vapour and dry-air molecular weight. $C$ is a turbulent transfer coefficient depending on surface roughness $z_{0}$ and on the stability of the surface boundary layer through a bulk Richardson number (Martin and Lejeune, 1998). $u_{\mathrm{a}}, T_{\mathrm{a}}, q_{\mathrm{a}}$ are the forced atmosperic wind speed, temperature and specific humidity. The temperature $T_{\mathrm{S}}$ is calculated closing the surface energy balance (Brun et al., 1989). The atmospheric moisture at the surface $q_{\mathrm{s}}$ is assumed to be that of air saturation at the temperature of the snow surface $T_{\mathrm{s}}$.

For $u_{\mathrm{a}}, T_{\mathrm{a}}$ and $q_{\mathrm{a}}$ : the third level of the mast is used. The mast provides several observation levels, allowing an alternative and independent evaluation of the turbulent fluxes using the profile method.

The profile method is a frequently used method for turbulent-flux estimations, using standard meteorological measurements at two levels. It is based on the "flux-gradient" relationship of the Monin-Obukhov (MO) similarity theory for the atmospheric surface layer (Monin and Obukhov, 1954).

Berkowicz and Prahm (1982) outlined the procedure for the estimations of the sensible heat and the momentum fluxes, SHF and $\tau$. It is adapted here for the latent heat flux (LHF) (Eq. 5). In the present study, heat fluxes towards the snow surface are counted as positive.

$$
\begin{aligned}
& \mathrm{SHF}=\rho c_{p} u_{*} \theta_{*} \\
& \mathrm{LHF}=\rho L_{\mathrm{s}} u_{*} q_{*} \\
& \tau=\rho u_{*}^{2},
\end{aligned}
$$

Table 1. Simulated 2010-2012 annual mean latent heat and water equivalent exchange at the surface in 4 Crocus snow-pack model runs using different input atmospheric surface boundary conditions: S1: Purely ECMWF data

S2: Observed data of temperature, relative humidity and wind, otherwise ECMWF data

S3: Observed data for temperature and relative humidity, otherwise ECMWF data, including wind speed

S4: Observed data for wind, otherwise ECMWF data, including temperature and moisture.

\begin{tabular}{lcc}
\hline Simulation & $\mathrm{W} \mathrm{m}^{-2}$ & $\mathrm{~cm}$ \\
\hline S1 & -25.7 & -31.3 \\
S2 & -11.1 & -13.4 \\
S3 & -13.0 & -15.8 \\
S4 & -23.9 & -29.1 \\
\hline
\end{tabular}

where $u_{*}, q_{*}$ and $\theta_{*}$ are characteristic scales of wind, specific humidity and potential temperature. They are computed from the measured gradients of wind speed, temperature and specific humidity, between levels $z_{2}$ and $z_{1}$, solving iteratively the following set of equations:

$$
\begin{aligned}
& u_{2}-u_{1}=\frac{u_{*}}{\kappa}\left[\ln \left(z_{2} / z_{1}\right)-\psi_{\mathrm{m}}\left(z_{2} / L\right)+\psi_{\mathrm{m}}\left(z_{1} / L\right)\right] \\
& \theta_{2}-\theta_{1}=\frac{\theta_{*}}{\kappa}\left[\ln \left(z_{2} / z_{1}\right)-\psi_{\mathrm{h}}\left(z_{2} / L\right)+\psi_{\mathrm{h}}\left(z_{1} / L\right)\right] \\
& q_{2}-q_{1}=\frac{q_{*}}{\kappa}\left[\ln \left(z_{2} / z_{1}\right)-\psi_{\mathrm{h}}\left(z_{2} / L\right)+\psi_{\mathrm{h}}\left(z_{1} / L\right)\right] \\
& L=\frac{u_{*}^{3}}{\kappa \frac{g}{T_{0}} \theta_{*} u_{*}} \simeq \frac{\text { mechanical production }}{\text { buoyant production }} .
\end{aligned}
$$

$L$ is the Monin-Obukhov length. The $\psi$ functions are the stratification corrections to the logarithmic profile (Berkowicz and Prahm, 1982; Andreas, 2002). We make the usual assumptions that $\psi_{\mathrm{h}}$ is the same for both temperature and humidity. In case of moist air, to account for the weight of water vapour, the potential temperature is replaced by the virtual potential temperature in the buoyancy term of the Monin-Obukhov length. In our case, to a first order, the air is approximately dry $q \sim 0.6 \mathrm{~g} \mathrm{~kg}^{-1} \rightarrow \theta_{\mathrm{v}}=(1+0.61 q) \cdot \theta \sim\left(1+0.37 \times 10^{-4}\right) \cdot \theta$, so that we assumed $\theta_{\mathrm{v}} \sim \theta$.

The MO theory, on which the profile method is based, was developed under the assumptions of horizontal homogeneity and stationarity. Both assumptions are questionable in a katabatic flow. In particular, in the MO theory, mechanical and buoyant forces are assumed to act only in the vertical direction, and the turbulent transport is neglected compared to the local mechanical and buoyancy productions. Munro and Davies (1978) raised the point that horizontal buoyancy gradients are precisely the driving force of a katabatic flow. Coupling between the dynamics and thermodynamics should be taken into account, but is not included in MO theory (Grisogono and Oerlemans, 2001). Denby and Greuell (2000) 
Table 2. The observed range and gradients (difference between levels 5 and 2 on the mast) of temperature, $\mathrm{RH}$ wri and wind speed, and factory stated range of instrumental accuracy.

\begin{tabular}{lllllll}
\hline & Sensor & \multicolumn{2}{c}{ Observations } & & \multicolumn{2}{c}{ Accuracy $( \pm)$} \\
\cline { 3 - 4 } & & Range & Gradient & & Range & Mean \\
\hline Temperature $\left({ }^{\circ} \mathrm{C}\right)$ & Vaisala HMP45 & -20 to -2 & -0.04 to 3.9 & & 0.2 to 0.4 & 0.35 \\
Relative humidity (\% wri) & Vaisala HMP45 & 30 to 100 & 0 to -18 & & 2 to 3 & 2.5 \\
Wind speed $\left(\mathrm{m} \mathrm{s}^{-1}\right)$ & Vektor A100LK & 0 to 30 & 0 to 4 & & 0.1 to 0.4 & 0.2 \\
\hline
\end{tabular}

compared fluxes obtained from profile and bulk calculation with results from a one-dimensional second-order-closure boundary-layer model. The model second-order prognostic equations account for the turbulent transport terms and the two components of the buoyancy terms, parallel and perpendicular to the sloped surface (Denby, 1999). The model proved able to reproduce observed eddy fluxes on two highlatitude glaciers (in particular). With the model as a reference, Denby and Greuell (2000) find a strong underestimation with the profile method, particularly when approaching the wind maximum. They conclude that the profile method should be restricted to measurements at heights below onethird of the height of the wind maximum. Furthermore, Grisogono et al. (2007) pointed out that, for slopes larger than $5^{\circ}$, the MO length may be larger than the height of the wind maximum and may thus miss the jet-related turbulence.

This is not likely in our case. The observed katabatic flow at the coast of Adélie Land is generated $1000 \mathrm{~km}$ upstream, so that, when reaching D17, the katabatic layer is thick. Radiosounding at Dumont d'Urville generally reports a jet height in the range of 50 to $500 \mathrm{~m}$ above the surface (Fig. 10a). The short mast is well below this. The first measurement-point height is 2 orders of magnitude greater than the roughness length $z_{0}$, itself 2 orders of magnitude greater than the viscosity length scale $u_{*} / \nu$. Wind profiles are quasi-logarithmic (Fig. 10b) and fairly consistent with the theoretical predictions of rough turbulent flow theories and, in particular, the MO theory. On the other hand, the mast shallowness limits the height over which gradients can be estimated, raising the issue of instrumental accuracy beyond blowing-snow cases.

Factory-stated instrumental accuracies are reported in Table 2 and compared with the observed gradients along the mast. Assuming that measurement errors follow a normal distribution, the propagation of the uncertainty to the moisture-flux estimate using the profile method can be evaluated using a Monte Carlo method. A set of 200 series, based on the records artificially contaminated by measurement uncertainties, are produced and the profile method is applied. At each time in the record, the spread (standard deviation) of the flux with the 200 series set is used as an estimate of the induced error. The contamination errors for each meteorological variable are randomly drawn from a normal distribution of a given standard deviation.

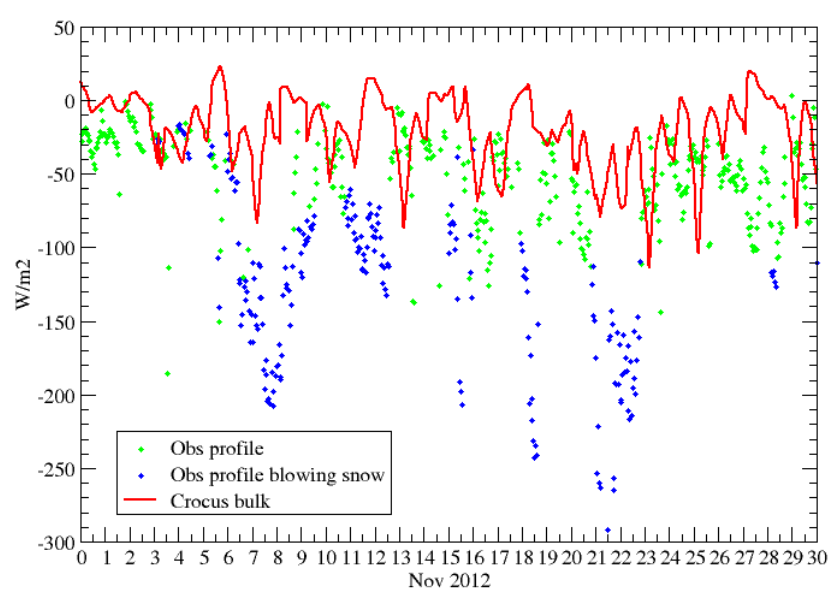

Figure 9. Surface latent heat flux in November 2012, evaluated from bulk parameterization in the Crocus model (red line) and from the profile method when blowing snow occurs (blue dots) or not (green dots).

\subsection{Results and discussion}

For November 2012, Fig. 9 compares the latent heat flux from Crocus (bulk parameterization) and the profile method, the latter using wind, moisture and temperature at second and fifth levels on the mast, which are separated by $2.5 \mathrm{~m}$. For the third level being used in the Crocus calculations, the bulk and profile evaluations are fully independent in terms of observation data input. A diurnal cycle shows clearly in the Crocus data: sublimation is positive during the day and often slightly negative (inverse sublimation) at night, when the snow surface cools. The profile calculations produce a less definite diurnal cycle and no inverse sublimation. The comparison emphasizes the large scatter of the profile-estimated fluxes. The standard deviation is much larger $\left(60 \mathrm{~W} \mathrm{~m}^{-2}\right)$ than in Crocus results $\left(22 \mathrm{~W} \mathrm{~m}^{-2}\right)$. Profile fluxes reach $-300 \mathrm{~W} \mathrm{~m}^{-2}$, while the Crocus results range from -180 to $22 \mathrm{~W} \mathrm{~m}^{-2}$. In Fig. 9, occurrences with and without blowing snow are distinguished. A FlowCapt threshold of $4 \mathrm{~g} \mathrm{~m}^{-2} \mathrm{~s}^{-1}$ is used to distinguish blowing from not-blowing snow events. This is much lower than the threshold used in Sect. 3 to separate the strongest blowing-snow cases. The threshold here allows one to characterize a strong impact of even light quantities 

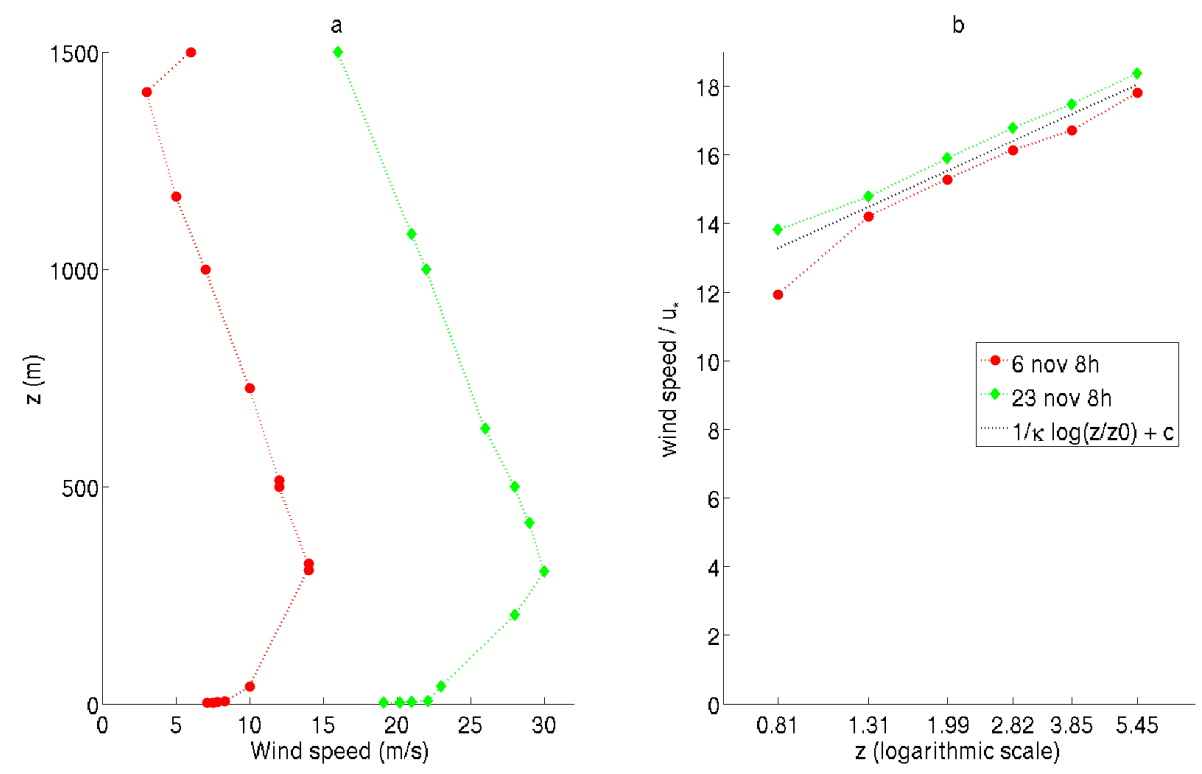

Figure 10. (a) Wind velocity profile from radiosounding performed at 08:00 LT (local time) on 6 and 23 November. (b) Normalized wind profile on a semi-log plot, from the $7 \mathrm{~m}$ mast data at 08:00 LT on 6 and 23 November.

of blowing snow on flux estimation by the profile method. The agreement between bulk and profile evaluations tends to be better when no blowing snow is detected: both exhibit comparable daily variability and standard deviation (22 and $27 \mathrm{~W} \mathrm{~m}^{-2}$, respectively). One may expect confidence in the profile method to decrease during blowing-snow events, because the vertical moisture gradients are weaker (Fig. 5), raising instrumental accuracy as a serious issue. The fact that the profile fluxes particularly diverge when blowing snow is detected may indicate such a difficulty.

Sensitivity experiments with several assumptions on measurement errors have been performed for November 2012. The results are summarized in Fig. 11. A relative humidity error of $2.5 \%$ induces a standard deviation of $\pm 50 \mathrm{~W} \mathrm{~m}^{-2}$ on the latent heat flux, up to $\pm 80 \mathrm{~W} \mathrm{~m}^{-2}$ in case of strong winds. For a temperature error of $0.35^{\circ} \mathrm{C}$, the standard deviation on latent heat fluxes averages $\pm 80 \mathrm{~W} \mathrm{~m}^{-2}$, often exceeding $\pm 200 \mathrm{~W} \mathrm{~m}^{-2}$. Because the observed temperature gradients are very small, measurement uncertainties induce comparatively large flux uncertainties. Figure 11 shows that humidity and temperature-measurement uncertainties have the largest direct repercussions on latent heat flux computations.

The uncertainties due to the different types of meteorological measurements are not easily comparable. We choose to set, on the $x$ axis, the input errors for temperature, relative humidity, wind speed and sensors height as multiples of a reference uncertainty for the corresponding variable. For meteorological variables, the factory stated accuracy is taken for the reference uncertainty. The factory stated accuracies depend on the values of the measured quantities: temperature, wind and relative humidity. We choose the mean over the studied period (Table 2). Because variations of sensor

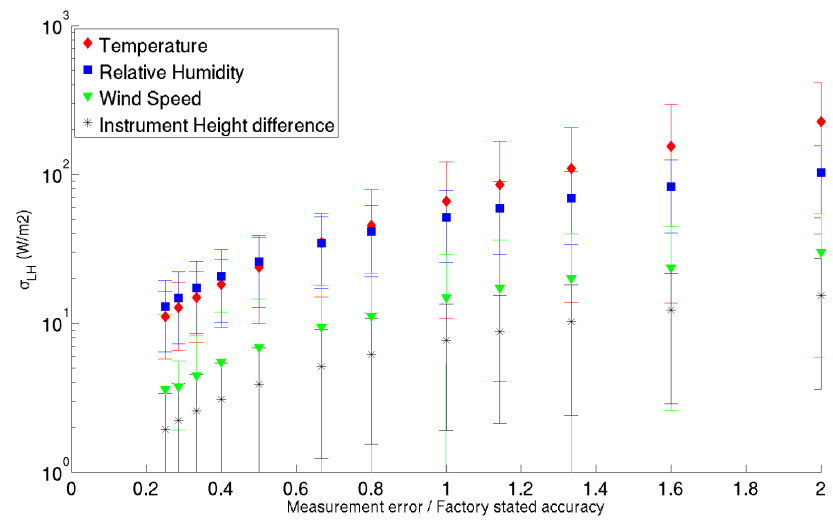

Figure 11. Uncertainty propagation into the latent heat flux from measurement uncertainties via profile calculations. The mean uncertainties in LHF are represented by symbols. Vertical bars illustrate the spread around the mean (standard deviation). On the $x$ axis, the measurement uncertainties of temperature (red diamond), relative humidity (blue square) and wind speed (green triangle) are reported as multiples of the factory-stated accuracies. For instrument height (black star), the uncertainty is reported as a multiple of the estimated accumulation during the month $(\sim 10 \mathrm{~cm})$. Note that a logarithmic scale is used on the $y$ axis.

height were not measured in November 2012, an estimate of the height of fresh snow, which could have accumulated until the next measurement in December, is made. Taking an average snowfall of $30 \mathrm{~mm}$ water equivalent per month in the area (Palerme et al., 2014), we estimate a height of snow approaching $10 \mathrm{~cm}$. This is a debatable choice for the reference uncertainty of the sensor height, but the fact that the 
impact of height errors are weak compared to those of temperature, wind velocity and humidity errors is way beyond this uncertainty.

A relative humidity error of $2.5 \%$ induces a standard deviation of $\pm 50 \mathrm{~W} \mathrm{~m}^{-2}$ on the latent heat flux, up to $\pm 80 \mathrm{~W} \mathrm{~m}^{-2}$ in case of strong winds. For a temperature error of $0.35^{\circ} \mathrm{C}$, the standard deviation on latent heat fluxes averages $\pm 80 \mathrm{~W} \mathrm{~m}^{-2}$, often exceeding $\pm 200 \mathrm{~W} \mathrm{~m}^{-2}$. Because the observed temperature gradients are very small, measurement uncertainties induce comparatively large flux uncertainties. Figure 11 shows that humidity and temperaturemeasurement uncertainties have the largest direct repercussions on latent heat flux computations.

The uncertainty propagation is amplified as the wind gets stronger, as illustrated in Fig. 12. This is primarily because fluxes are computed proportional to the wind scale $u_{*}$ (Eq. 5). Secondly, strong mixing and blowing snow during strong winds induce a decrease in the temperature and humidity gradients, so that measurement uncertainties become important compared to gradients, leading to a heightened uncertainty propagation. This is supported by Fig. 12a and b, which show that the propagated uncertainties are amplified with wind velocity or decreasing temperature gradients.

In addition, strong wind episodes generally go along with an increase of relative humidity (Fig. 5). When approaching $100 \%$ of relative humidity, accuracy of the Humicap sensor deteriorates ( $\pm 2 \%$ to $\pm 3 \%)$.

This study demonstrates a strong sensitivity of the profile method to measurement errors, particularly in the case of small gradients in conjunction with strong winds. Special attention has to be devoted to temperature measurements. In Fig. 9, discrepancies between the latent heat fluxes, calculated with the two methods, on the 7 and 23 November may be explained by enhanced uncertainties permitted by the strong wind episode (Fig. 10a). Nonetheless, discriminating the part of uncertainty propagation due to strong wind and that of computation inaccuracies due to the presence of blowing snow is not straightforward. The Crocus model uses both a bulk method, which is essentially an integrated form of profile method, and surface energy budget closure to compute the surface temperature. As such, the Crocus calculations are less prone to measurement-error amplifications and then more reliable in the present working conditions.

Finally, one more issue should be raised here with respect to the profile method calculations in the case of blowing snow: the direct impact of airborne snow on vertical gradients of air density on the evaluation of the MO length. Snow sublimates, which cools the air, increases its density and affects density gradients depending on blown-snow concentration gradients; this is the temperature effect, which is accounted for because the temperatures are measured. Density gradients are also affected because ice is denser than the air; the weight of an air parcel is the sum of that of the air and of the ice within the parcel. As the concentration of blown snow decreases with height, this has a stabilizing effect (Kodama
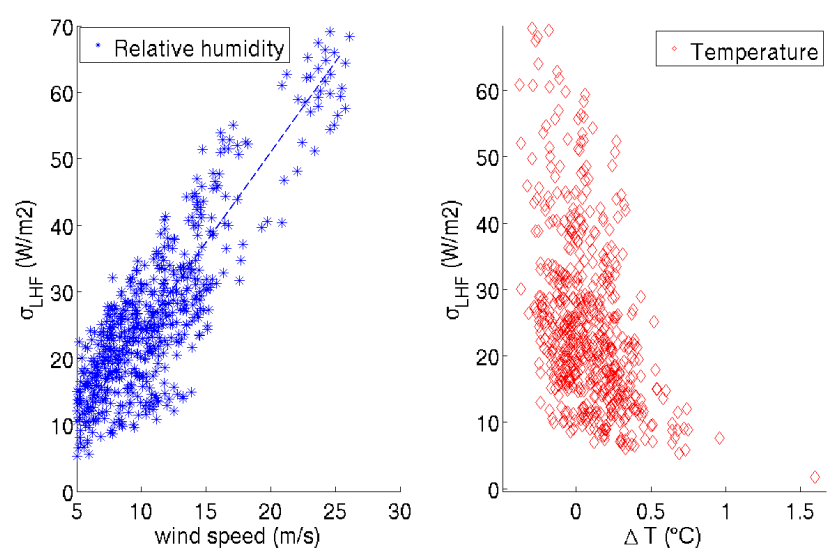

Figure 12. Uncertainty propagation into the latent heat flux from measurements uncertainties via profile calculations. (a) Propagated uncertainties into LHF versus wind speed: results of a Monte Carlo experiment starting with an error of $\pm 2.5 \%$ for relative humidity (blue square). (b) Propagated uncertainties into LHF versus temperature gradients (difference between level 5 and level 2). Results of a Monte Carlo experiment starting with an error of $\pm 0.35^{\circ}$ for temperature (red diamond).

et al., 1985; Gosink, 1989) and decreases the MO length. In that case, in the profile calculations, one should directly consider the density (including the blown-snow effect), rather than the potential temperature. Uncertainties on blown-snow concentration measurements (Sect. 2.1) are too large to expect a reasonable estimation of the density gradient. Consequently, this particular point is not addressed here.

\section{Discussion and conclusion}

Stearns and Weidner (1993) report calculated latent heat flux for several AMRC AWSs, using both the station-recorded temperature, moisture and wind, and a bulk parameterization. The results range from close to 0 or even inverse sublimation (water deposition, positive heat flux for the surface), to $-21 \mathrm{~W} \mathrm{~m}^{-2}$, generally significantly less in absolute value than found here for D17 if the ECMWF meteorology is used. However, Stearns and Weidner (1993) results are for sites on the Ross Ice Shelf, none of which being as directly exposed to katabatic winds as D17. A limited survey of published evaluations of monthly or seasonal observed latent heat flux in Antarctica is provided by van den Broeke (1997). The numbers again range from virtually 0 to $-22 \mathrm{~W} \mathrm{~m}^{-2}$, and again in better agreement with results in Table 1 if the observed, rather than the analysed, meteorology is used. Quoting Genthon et al. (2007), who present observed and modelled time series of surface snow and ice balance over a coastal blue-ice field in Adélie Land near D17, "sublimation [...] accounts for $38 \mathrm{~cm} \mathrm{[...]} \mathrm{possibly} \mathrm{overestimated}$ due to missing sublimation of blown snow and saturation effect [in the model used]". This figure accounts for a period 
of 2 years, in 2004-2005. Considering differences between the blue-ice field and snow-covered D17 site, including, in particular, differences in albedo (bare ice has a much lower albedo than snow), this is consistent with the numbers in Table 1 . The words of caution about atmospheric-moisture saturation prove appropriate.

The observations at D17 do confirm a strong saturation effect of blowing snow in the near-surface atmosphere. This is because the suspended snow is efficiently ventilated and sublimation takes place in the full air layer. Snow particles that remain at the surface are not as well ventilated and subject to sublimation. If the ECMWF analyses provided a good estimate of the surface-air-moisture content if there was no blowing snow, surface sublimation would be greatly increased, but still only remove 40 to $50 \mathrm{~cm}$ of water over 3 years. This is estimated using a bulk parameterization of surface sublimation in the Crocus snow-pack model. Although profiles of meteorology, including atmospheric moisture, are available, this cannot be confidently used for the evaluation of turbulent moisture flux and sublimation, because the profile method is not strongly grounded in katabatic conditions, including in the presence of blowing snow. In practice, it is highly sensitive to measurement inaccuracies. In agreement with Denby and Greuell (2000), one can recommend using the bulk parameterization in such conditions. The issue of measuring surface temperature is avoided here, as this is calculated by the Crocus model by closing the energy-balance equation.

The simulated/observed net snow accumulation is $\sim 180 \mathrm{~cm}$ over 3 years. According to the model, which continuously calculates snow density in fair agreement with the sporadic in situ measurements near the surface, this converts into $93 \mathrm{~cm}$ of water equivalent (from the model run combining ECMWF and observed meteorology). The cumulated precipitation (accounting for the multiplication factor used in the model) amounts to $2 \mathrm{~m}$. Thus, more than half of the snowfall, equivalent to more than $1 \mathrm{~m}$ of water, is lost through either surface sublimation or erosion and export (either solid or as evaporated moisture). The GLACIOCLIM-SAMBA data do show that the SMB increases from the coast to $\sim 30 \mathrm{~km}$ inland (Agosta et al., 2012). This is not because snowfall largely increases over such a short distance, but rather because surface sublimation and blowing snow (including sublimation) remove a large part of the deposited snow, in a way that varies with wind speed and other near-surface meteorological variables.

Acknowledgements. We wish to thank J. Lenaerts and M. Frezzotti for their comments which helped to improve the paper. This work was supported by funding by the ICE2SEA programme from the European Union 7 framework programme, grant number 226375. This paper is ICE2SEA contribution number 179. Additional support by INSU through the LEFE/CLAPA project and OSUG through the CENACLAM/GLACIOLCIM observatory is also acknowledged. Field observations would not have been possible without the logistical support and additional funding by the French polar institute IPEV (programme CALVA/1013).

Edited by: M. van den Broeke

\section{References}

Agosta, C., Favier, V., Genthon, C., Gallée, H., Krinner, G., Lenaerts, J. T., and van den Broeke, M. R.: A 40-year accumulation dataset for Adelie Land, Antarctica and its application for model validation, Clim. Dynam., 38, 75-86, 2012.

Anderson, P. S.: Reply, J. Atmos. Ocean. Tech., 13, 913-914, 1996.

Andreas, E. L.: Parameterizing Scalar Transfer over Snow and Ice: A Review, J. Hydrometeorol., 3, 417-432, 2002.

Andreas, E. L.: The Fallacy of Drifting Snow, Bound.-Lay. Meteorol., 141, 333-347, 2011.

Berkowicz, R. and Prahm, L.: Evaluation of the profile method for estimation of surface fluxes of momentum and heat, Atmos. Environ., 16, 2809-2819, 1982.

Bintanja, R.: Snowdrift sublimation in a katabatic wind region of the Antarctic ice sheet, J. Appl. Meteorol., 40, 1952-1966, 2001.

Bintanja, R. and van den Broeke, M. R.: Momentum and scalar transfer coefficients over aerodynamically smooth antarctic surfaces, Bound.-Lay. Meteorol., 74, 89-111, 1995.

Brun, E., Martin, E., Simon, V., Gendre, C., and Coleou, C.: An energy and mass model of snow cover suitable for operational avalanche forecasting, J. Glaciol., 35, 333-342, 1989.

Brun, E., David, P., Sudul, M., and Brunot, G.: A numerical model to simulate snow-cover stratigraphy for operational avalanche forecasting, J. Glaciol., 38, 13-22, 1992.

Cierco, F.-X., Naaim-Bouvet, F., and Bellot, H.: Acoustic sensors for snowdrift measurements: How should they be used for research purposes?, Cold Reg. Sci. Technol., 49, 74-87, selected Papers from the General Assembly of the European Geosciences Union (EGU), 25 April 2005, Vienna, Austria, 2007.

Dang, H., Genthon, C., and Martin, E.: Numerical modelling of snow cover over polar ice sheets, Ann. Glaciol., 25, 170-176, 1997.

Das, I., Bell, R. E., Scambos, T. A., Wolovick, M., Creyts, T. T., Studinger, M., Frearson, N., Nicolas, J. P., Lenaerts, J. T. M., and van den Broeke, M. R.: Influence of persistent wind scour on the surface mass balance of Antarctica, Nat. Geosci., 6, 367-371, 2013.

Denby, B.: Second-Order Modelling of Turbulence in Katabatic Flows, Bound.-Lay. Meteorol., 92, 65-98, 1999.

Denby, B. and Greuell, W.: The use of bulk and profile methods for determining surface heat fluxes in the presence of glacier winds, J. Glaciol., 46, 445-452, 2000.

Déry, S. J. and Yau, M. K.: Large-scale mass balance effects of blowing snow and surface sublimation, J. Geophys. Res.-Atmos., 107, 8.1-8.17, 2002.

ECMWF: Physical Parametrization, ECMWF Forecast Model, Research Manual RM-3, 3rd Edn., Tech. rep., ECMWF, http:// data-portal.ecmwf.int/*, 1989.

Frezzotti, M., Pourchet, M., Flora, O., Gandolfi, S., Gay, M., Urbini, S., Vincent, C., Becagli, S., Gragnani, R., Proposito, M., Severi, M. T. R., Udisti, R., and Fily, M.: New Estimations of Precipitation and Surface Sublimation in East Antarctica from Snow Accumulation Measurements, Cim. Dynam., 23, 803-813, 2004. 
Gallée, H., Peyaud, V., and Goodwin, I.: Simulation of the net snow accumulation along the Wilkes Land transect, Antarctica, with a regional climate model, Ann. Glaciol., 41, 17-22, 2005.

Gallée, H., Trouvilliez, A., Agosta, C., Genthon, C., Favier, V., and Naaim-Bouvet, F.: Transport of Snow by the Wind: A Comparison Between Observations in Adélie Land, Antarctica, and Simulations Made with the Regional Climate Model MAR, Bound.Lay. Meteorol., 146, 133-147, 2013.

Genthon, C., Fily, M., and Martin, E.: Numerical simulations of Greenland snowpack and comparison with passive microwave spectral signatures, Ann. Glaciol., 32, 109-115, 2001.

Genthon, C., Kaspari, S., and Mayewski, P.: Interannual variability of the surface mass balance of West Antarctica from ITASE cores and ERA40 reanalyses, 1958-2000, Clim. Dynam., 24, 759-770, 2005.

Genthon, C., Lardeux, P., and Krinner, G.: The surface accumulation and ablation of a coastal blue-ice area near Cap Prudhomme, Terre Adélie, Antarctica, J. Glaciol., 53, 635-645, 2007.

Genthon, C., Six, D., Favier, V., Lazzara, M., and Keller, L.: Atmospheric Temperature Measurement Biases on the Antarctic Plateau, J. Atmos. Ocean. Tech., 28, 1598-1605, 2011.

Genthon, C., Six, D., Gallée, H., Grigioni, P., and Pellegrini, A.: Two years of atmospheric boundary layer observations on a 45$\mathrm{m}$ tower at Dome $\mathrm{C}$ on the Antarctic plateau, J. Geophys. Res.Atmos., 118, 3218-3232, doi:10.1002/jgrd.50128, 2013.

Goff, J. A. and Gratch, S.: Thermodynamics properties of moist air, Trans. Am. Soc. Heat. Ventil. Eng., 51, 125-157, 1945.

Gosink, J.: The extension of a density current model of katabatic winds to include the effects of blowing snow and sublimation, Bound.-Lay. Meteorol., 49, 367-394, 1989.

Grisogono, B. and Oerlemans, J.: A theory for the estimation of surface fluxes in simple katabatic flows, Q. J. Roy. Meteorol. Soc., 127, 2725-2739, 2001.

Grisogono, B., Kraljević, L., and Jeričević, A.: The low-level katabatic jet height versus Monin-Obukhov height, Q. J. Roy. Meteorol. Soc., 133, 2133-2136, 2007.

Kodama, Y., Wendler, G., and Gosink, J.: The effect of blowing snow on katabatic winds in Antarctica, Ann. Glaciol., 6, 59-62, 1985.

Lenaerts, J. T. M., van den Broeke, M. R., Déry, S. J., van Meijgaard, E., van de Berg, W. J., Palm, S. P., and Sanz Rodrigo, J.: Modeling drifting snow in Antarctica with a regional climate model: 1. Methods and model evaluation, J. Geophys. Res.Atmos., 117, doi:10.1029/2011JD016145, 2012a.

Lenaerts, J. T. M., van den Broeke, M. R., van de Berg, W. J., van Meijgaard, E., and Kuipers Munneke, P.: A new, high-resolution surface mass balance map of Antarctica (1979-2010) based on regional atmospheric climate modeling, Geophys. Res. Lett., 39, L04501, doi:10.1029/2011GL050713, 2012b.
Ligtenberg, S., Lenaerts, J., Van den Broeke, M., and Scambos, T.: On the formation of blue ice on Byrd Glacier, Antarctica, J. Glaciol., 60, 41-50, 2014.

Mann, G. W., Anderson, P. S., and Mobbs, S. D.: Profile measurements of blowing snow at Halley, Antarctica, J. Geophys. Res.Atmos., 105, 24491-24508, 2000.

Martin, E. and Lejeune, Y.: Turbulent fluxes above the snow surface, Ann. Glaciol., 26, 179-183, 1998.

Mawson, D.: The home of the blizzard, a true story of Antarctic survival: The story of the Australian Antarctic expedition 19111914, Wakefield Press, Australia, 1915.

Monin, A. and Obukhov, A.: Basic laws of turbulent mixing in the surface layer of the atmosphere, Tr. Akad. Nauk SSSR Geophiz, 24, 163-187, 1954.

Munro, D. and Davies, J.: On fitting the log-linear model to wind speed and temperature profiles over a melting glacier, Bound.Lay. Meteorol., 15, 423-437, 1978.

Palerme, C., Kay, J. E., Genthon, C., L'Ecuyer, T., Wood, N. B., and Claud, C.: How much snow falls on the Antarctic ice sheet?, The Cryosphere, 8, 1577-1587, doi:10.5194/tc-8-1577-2014, 2014.

Parish, T. R. and Bromwich, D. H.: Continental-Scale Simulation of the Antarctic Katabatic Wind Regime, J. Climate, 4, 135-146, 1991.

Schmidt, R.: Vertical profiles of wind speed, snow concentration, and humidity in blowing snow, Bound.-Lay. Meteorol., 23, 223 246, 1982.

Stearns, C. R. and Weidner, G. A.: Sensible and latent heat flux estimates in Antarctica, in Antarctic Meteorology and Climatology, Antarct. Res. Ser., 61, 109-138, 1993.

Tabler, R.: Estimating the Transport and Evaporation of Blowing Snow, in: vol. 73 of Snow Management on Great Plains Agricultural Council, University of Nebraska Agricultural Experiment Station, Lincoln, 1975.

Trouvilliez, A.: Observation et modélisation de la neige soufflée en Antarctique, Ph.D. thesis, Grenoble University, Grenoble, 2013.

Trouvilliez, A., Naaim, F., Genthon, C., Piard, L., Favier, V., Bellot, H., Agosta, C., Palerme, C., Amory, C., and Gallée, H.: Blowing snow observation in Antarctica: A review including a new observation system in Adélie Land, Cold Reg. Sci. Technol., doi:10.1016/j.coldregions.2014.09.005, in press, 2014.

van den Broeke, M. R.: Spatial and temporal variation of sublimation on Antarctica: Results of a high-resolution general circulation model, J. Geophys. Res.-Atmos., 102, 29765-29777, 1997.

Wendler, G., Andre, J., Pettre, P., Gosink, J., and Parish, T.: Katabatic winds in Adélie Coast, in Antarctic Meteorology and Climatology, Antarct. Res. Ser., 61, 23-46, 1993.

Wendler, G., Stearns, C., Weidner, G., Dargaud, G., and Parish, T.: On the extraordinary katabatic winds of Adélie Land, J. Geophys. Res.-Atmos., 102, 4463-4474, 1997. 